\title{
Human-induced vibration of steel-concrete composite floors
}

Shiming Chen PhD

Professor, College of Civil Engineering, Tongji University, Shanghai, China (corresponding author: chensm@tongji.edu.cn)

\section{Rui Zhang MEng}

Doctoral Candidate, College of Civil Engineering, Tongji University,

Shanghai, China
Jie Zhang MEng

Doctoral Candidate, Department of Civil Engineering, University of Leuven, Leuven, Belgium

Long-span composite floors have many desirable properties and have been increasingly employed in building construction. However, these long-span structures are prone to excessive and complex vibration under human rhythmic activities such as walking, running, jumping and aerobics, which may result in people's discomfort and complaints. A finite-element numerical study was conducted to investigate the vibration behaviour of profiled steel-deck composite floors under human walking and rhythmic activities. The results indicate that human-induced vibration of composite floors is influenced by several factors, namely the load model, the floor's natural frequency, effective weight and damping ratio. In a multi-unit floor system, higher modes may be excited and these vibration components should be considered. In addition, the vibration responses of both the active unit and adjacent passive units should be taken into consideration under human walking or rhythmic activities. In multi-floor buildings, the vibration of adjacent passive floors under rhythmic activities should be considered. The comfort index can be used to evaluate human perception to the vibration of composite floors. One important step in this procedure is to determine the peak accelerations of composite floors, which can be achieved based on the developed finite-element models.

\section{Notation}

$f_{\mathrm{p}}$

$G$

H

$i$

P

$T_{\mathrm{p}}$

$t$

$t_{\mathrm{b}}$

$t_{\mathrm{p}}$

$t_{\mathrm{t}}$

$t_{\mathrm{W}}$

$w_{\mathrm{p}}$

$\alpha$

$\alpha_{i}$

$\phi_{i}$

\section{Introduction}

Long-span composite floors are increasingly being employed in building construction due to their small structural height and low self-weight. Compared with a traditional concrete floor, a composite floor has the characteristics of low rigidity, low natural frequencies and small damping ratio. However, under human activities, composite floors are prone to vibration, which can cause people's discomfort and complaint. Some design recommendations for floor vibration have been proposed in previous research studied. The American Institute of
Steel Construction takes peak acceleration as the evaluation index and the beam analogy method is used in calculations (AISC, 1997). The UK Steel Construction Institute proposes root-mean-square acceleration with frequency weighting for evaluation (SCI, 2009), and model shapes and the difference between the exciting and response points are considered. BS 6472-1:2008 (BSI, 2008) takes the vibration dose value as the evaluation index, considering the effect of continuous, intermittent and transient loads. Unfortunately, these guidelines are approximate because they are based on simplified structural models that cannot be used to simulate the multimodal vibration response of multi-unit steel-deck composite floors under pattern loading.

Many excitation sources may generate excessive vibrations in a lightly damped lightweight long-span floor, which may cause discomfort to the users of residential, commercial and public buildings. Among these vibration sources, those produced by human activities such as walking are the most common. Racic et al. (2009) presented a comprehensive review of the literature on human walking forces. Fourier series have been used to simulate human-induced forces, with the walking-induced force only varying with time, and different harmonics of the Fourier series were used for different human activities (AISC, 1997). Mello et al. (2008) discussed four kinds of walking loads - two of which changed with time only, while the other two were modelled considering the effects of both time and position. $\mathrm{Ji}$ and Ellis (1994) analysed the forces induced by dancing and aerobics. The load-time histories of these rhythmic activities were expressed as half-sine pulses and their Fourier series counterparts were analysed. 
Experimental studies and finite-element (FE) analyses have been conducted by many researchers to investigate the behaviour of floor vibration. Ebrahimpour and Sack (2003) summarised the historical developments in the modelling of human dynamic loads, the perception criteria used in structural floor vibrations and the techniques used to mitigate human-induced vibrations. Pavic et al. (2007) presented the results of a combined experimental and analytical approach to investigate the modal properties of a composite floor of a lively open-plan office. Floor-column FE models were proposed by El-Dardiry and Ji (2006) and El-Dardiry et al. (2002) for determining a floor's vibration behaviour. Silva and Thambiratnam (2009, 2011) conducted a numerical study on multi-panel steel-deck composite floor systems to investigate the dynamic characteristics under dance-type human loads, and this work was further discussed by Chen and Zhang (2012). Liu and Davis (2012) investigated prediction methods for the vibration of high-frequency floors. Costa-Neves et al. (2014) evaluated the structural behaviour of composite floors subjected to dynamic excitations induced by human rhythmic activities. Using FE analysis, Behnia et al. (2013) proposed a methodology for assessing the dynamic responses of composite floors and determining the corresponding level of comfort.

In order to avoid unwanted vibrations under human rhythmic activities, structural engineers may consider taking measures in the structural design stage, such as improving the structural stiffness or even decreasing the mass system so that the fundamental natural frequency shifts away from the excitation frequency. However, it is not always possible to make significant changes in structural elements due to architectural or even economic factors. Considering these limitations, several researchers have proposed the use of vibration control devices associated with the main structural system (An et al., 2015, 2016; Gaspar et al., 2016; Reynolds et al., 2009; Santos et al., 2013; Varela and Battista, 2011). At present, two types of dynamic control devices are common - active and passive control devices. Both can provide significant reductions in vibration amplitudes and considerably improve the dynamic characteristics of a structure and therefore user comfort (Varela and Battista, 2011).

In work reported in this paper, a FE numerical study was conducted to investigate the vibration behaviour of steel-deck composite floors under human walking and rhythmic activities. The results obtained indicate that human-induced vibration of composite floors is influenced by several factors, namely, the load model, the floor's natural frequency, effective weight and damping ratio. In a multi-unit floor system, higher modes may be excited and those vibration components should be considered. In addition, the vibration responses of both the active unit and adjacent passive units should be taken into consideration under human walking or rhythmic activities. In multifloor buildings, the vibration of adjacent passive floors under rhythmic activities should be considered.

\section{Structural model and FE models}

\subsection{Structural model}

Two types of floor structures were considered in this study - a one-unit floor and a four-unit floor, as shown in Figures 1 and 2 respectively. Both comprised a composite slab of $150 \mathrm{~mm}$ thickness, with $0.8 \mathrm{~mm}$ thick profiled steel sheet. The composite floor was supported underneath by I-beams. The profiled steel sheet type was YX-70-200-600, as shown in Figure 3 . The primary beams (B1) were I-45 beams, positioned along the edge parallel to the spanning direction, and the secondary beams (B2) were I-40 beams simply supported across

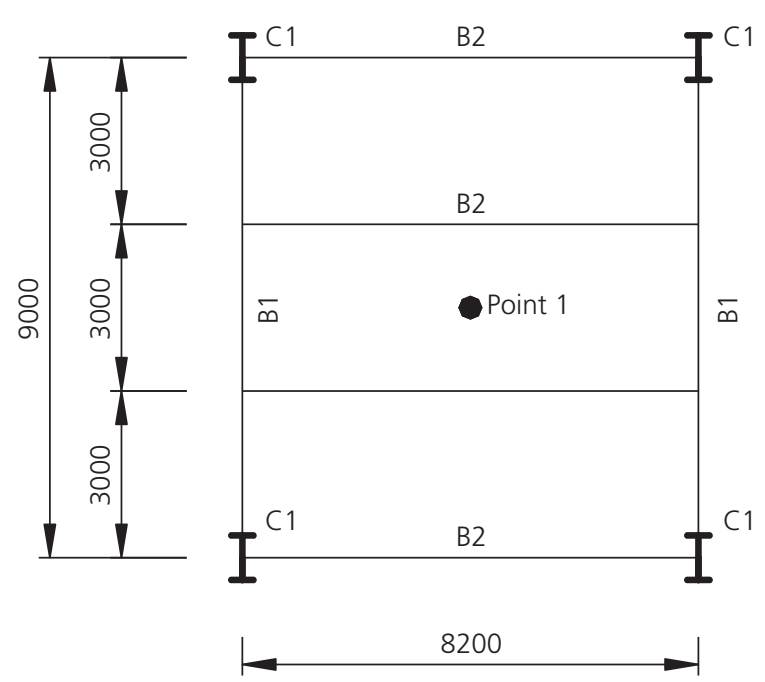

Figure 1. Configuration of one-unit floor (dimensions in $\mathrm{mm}$ )

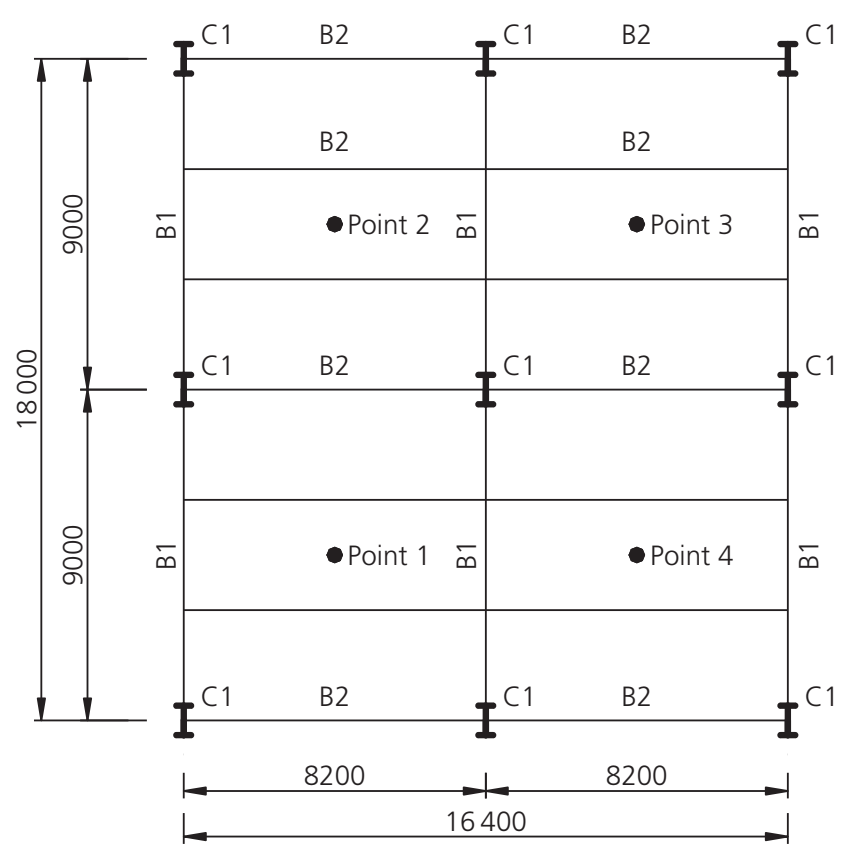

Figure 2. Configuration of four-unit floor (dimensions in $\mathrm{mm}$ ) 
the primary beams. The columns $(\mathrm{C} 1)$ were the same size as the secondary beams (B2). The four-unit floor system covered a floor area of $16 \cdot 4 \times 18 \mathrm{~m}$. Details of the different sections of the beams and the columns are given in Table 1.

\subsection{Finite-element models}

The floor-column model was considered by El-Dardiry et al. (2002) to be the most appropriate model to study the dynamic behaviour of long-span flat floors supported by columns, and a floor-column model was thus used in this investigation. The

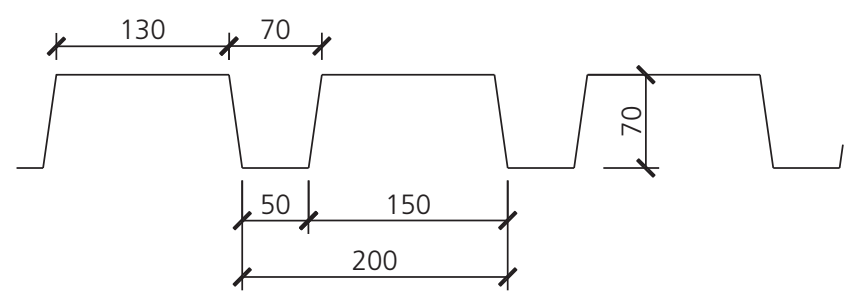

Figure 3. Cross-section of steel sheet $(0.8 \mathrm{~mm}$ thick)

Table 1. Geometrical characteristics of the beam and column sections

\begin{tabular}{|lccccc|} 
Section type & $\boldsymbol{H}: \mathbf{m m}$ & $\boldsymbol{B}: \mathbf{m m}$ & $\boldsymbol{t}_{\mathbf{t}}: \mathbf{m m}$ & $\boldsymbol{t}_{\mathbf{b}}: \mathbf{m m}$ & $\boldsymbol{t}_{\mathbf{w}}: \mathbf{m m}$ \\
\hline I-36 & 360 & 145 & $12 \cdot 3$ & $12 \cdot 3$ & $7 \cdot 5$ \\
I-40 & 400 & 155 & $13 \cdot 0$ & $13 \cdot 0$ & $8 \cdot 0$ \\
I-45 & 450 & 160 & $14 \cdot 2$ & $14 \cdot 2$ & $8 \cdot 6$ \\
I-50 & 500 & 170 & $15 \cdot 2$ & $15 \cdot 2$ & $9 \cdot 5$ \\
I-55 & 550 & 180 & $16 \cdot 5$ & $16 \cdot 5$ & $10 \cdot 3$ \\
I-60 & 600 & 190 & $17 \cdot 8$ & $17 \cdot 8$ & $11 \cdot 1$ \\
I-65 & 650 & 200 & $19 \cdot 2$ & $19 \cdot 2$ & $12 \cdot 0$ \\
\hline
\end{tabular}

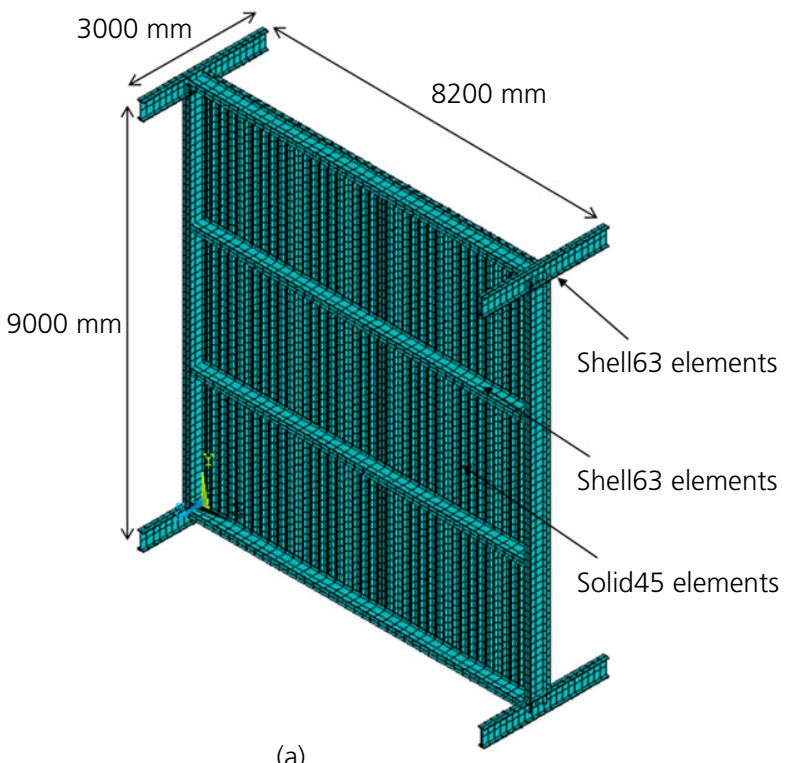

(a)

Figure 4. FE models of (a) one-unit floor system and (b) four-unit floor system column was taken as $1.5 \mathrm{~m}$ long above and below floor level (approximately a half-storey height in a conventional building) and fixed boundary conditions were assumed at the two ends of the column. FE models of the one-unit and four-unit floors were developed using Ansys 12.0 software. The concrete slab was modelled using the solid element Solid45 and the steel deck, including the ribs, was modelled using shell elements (Shell63). By merging the nodes for the two element types at the interface, the concrete slab was assumed to connect to the steel deck with no slip between these two materials. Considering the effect of torsional deformation and shear deformation, the primary and secondary beams and columns were all modelled using beam elements (Beam189). The composite slab, steel beams and columns were linked together by coupling the degrees of freedom.

It was found that more than 15000 elements were needed for accurate results in this FE model for both static and free vibration analysis, as noted by Silva (2006). Suitable mesh sizes were thus selected: the surface mesh was from $25 \times 30 \mathrm{~mm}$ to $40 \times 50 \mathrm{~mm}$ while the solid mesh was of size $25 \times 30 \times 40 \mathrm{~mm}$. The FE models of the one- and four-unit floors are shown in Figure 4.

Table 2 lists the material properties used in the analysis, which were obtained from material tests carried out in the Structural Laboratory at Tongji University. However, in the situation of a composite floor subjected to dynamic excitation, the concrete becomes stiffer than when it is subjected to static loads. Therefore, as the dynamic elastic modulus, the conventional concrete Young's modulus was increased by $35 \%$, as per AISC (1997).

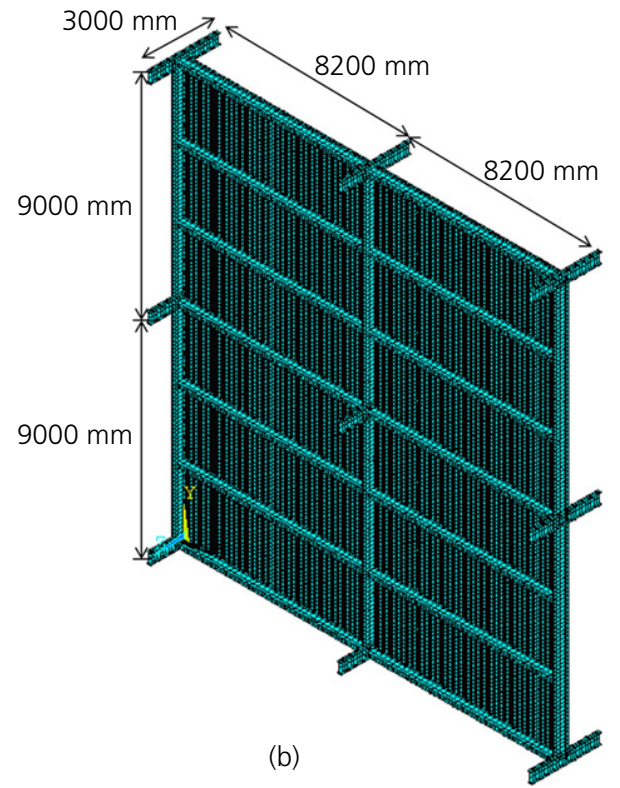


Table 2. Material properties of the floor system

\begin{tabular}{|lccc|} 
Material & $\begin{array}{c}\text { Young's } \\
\text { modulus: GPa }\end{array}$ & $\begin{array}{c}\text { Poisson's } \\
\text { ratio }\end{array}$ & $\begin{array}{c}\text { Material } \\
\text { density: } \mathbf{k g} / \mathbf{m}^{\mathbf{3}}\end{array}$ \\
\hline Steel & 205 & 0.3 & 8000 \\
Concrete & 32 & 0.2 & 2428 \\
\hline
\end{tabular}

\subsection{Verification of the FE model}

The computational techniques used in the modelling and analysis of the composite floor were validated by comparing the numerical results of the model analysis of a four-unit floor system with those from the literature (Silva and Thambiratnam, 2011). Figure 5 shows the first three modes and frequencies obtained from FE analysis. The first three frequencies calculated in the literature were $4 \cdot 0,5 \cdot 4$ and $5.9 \mathrm{~Hz}$. The results from the model analysis thus generally compared well with the existing results and the verified FE models were used in further analysis.

\section{Walking-induced floor vibrations}

\subsection{Human walking on a one-unit floor}

Free vibration analyses of the structural models were first carried out to determine their natural frequencies and the corresponding mode shapes. The first four natural frequencies of the one-unit floor were determined to be 5.18, 9.14, 9.46 and $12 \cdot 39 \mathrm{~Hz}$. Various frequencies for different human activities have been discussed in the literature and the human walking frequency falls in the range $1 \cdot 6-2 \cdot 4 \mathrm{~Hz}$ (Varela and Battista, 2011). Considering the most unfavourable situation, the walking frequency was taken as $5 \cdot 18 / 3=1 \cdot 73 \mathrm{~Hz}$. Thus, the third harmonic frequency of the load was the same as the fundamental frequency of the floor and a resonant response would be easily excited. The load was applied on the mid-span of the floor (point 1 in Figure 1), which gave the maximum deflection and acceleration values. The load was expressed by Equation 1 (AISC, 1997) and the first four harmonics were taken into consideration.
1. $F(t)=P\left[1+\sum \alpha_{i} \cos \left(2 \pi i f_{\mathrm{p}} t+\phi_{i}\right)\right]$

The damping ratio was taken as 0.03 in this analysis. The time history-acceleration response of point 1 and its Fourier amplitude spectrum are shown in Figure 6. The peak acceleration was $0.064 \mathrm{~m} / \mathrm{s}^{2}$, which exceeds the allowable acceleration for residential and office buildings of $0.050 \mathrm{~m} / \mathrm{s}^{2}$ (AISC, 1997). The time domain curve was converted into a frequency domain curve by means of Fourier transformation, and spectrum analysis was carried out to obtain the acceleration spectrum of point 1. Figure 6(b) shows that the acceleration response of the one-unit floor system excited by the third-order harmonic component of the load was the most drastic, with a corresponding frequency of about $5 \cdot 2 \mathrm{~Hz}$.

\subsection{Human walking on a four-unit floor}

The first four natural frequencies of the four-unit floor were $4 \cdot 87,5 \cdot 96,6 \cdot 54$ and $6 \cdot 85 \mathrm{~Hz}$. The walking frequency was taken as $4 \cdot 87 / 3=1.62 \mathrm{~Hz}$ and the load was applied at point 1 . The time history-acceleration responses and the acceleration spectra of the four-unit floor systems are shown in Figures 7 and 8, respectively, where points 1-4 points correspond to the middle positions of the four units, as shown in Figure 2.

The peak accelerations of points $1-4$ were $0.032,0.029,0.025$ and $0.020 \mathrm{~m} / \mathrm{s}^{2}$, respectively. The peak acceleration of the active unit (point 1) where the load was applied was larger than that of the passive units (points 2-4), but not significantly larger. In a multi-unit floor system where different floor units have different uses, the vibration of both the active unit and its adjacent units should be considered because the allowable acceleration varies with the use of the floor.

According to the acceleration spectra shown in Figure 8, the peak acceleration at each point appeared at two frequencies, $4.9 \mathrm{~Hz}$ and $6.5 \mathrm{~Hz}$, meaning that the first and third modes $(4 \cdot 87 \mathrm{~Hz}$ and $6.54 \mathrm{~Hz})$ were excited by the third and fourth harmonics of the load. For points 1 and 2, the third mode of

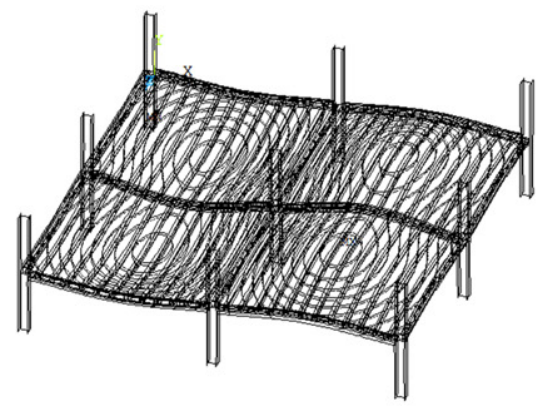

(a)

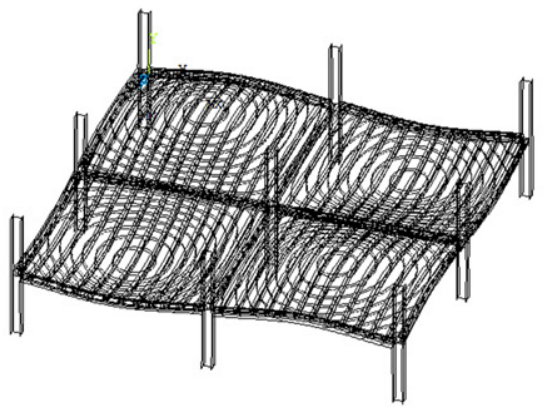

(b)

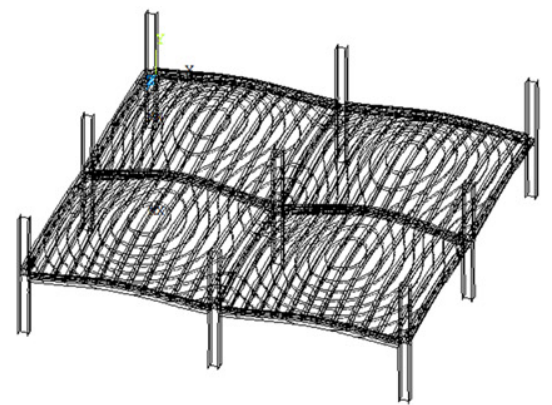

(c)

Figure 5. Mode shapes and frequencies of four-unit floor model: (a) first mode at $3.94 \mathrm{~Hz}$; (b) second mode at $5.26 \mathrm{~Hz}$; (c) third mode at $5.75 \mathrm{~Hz}$ 


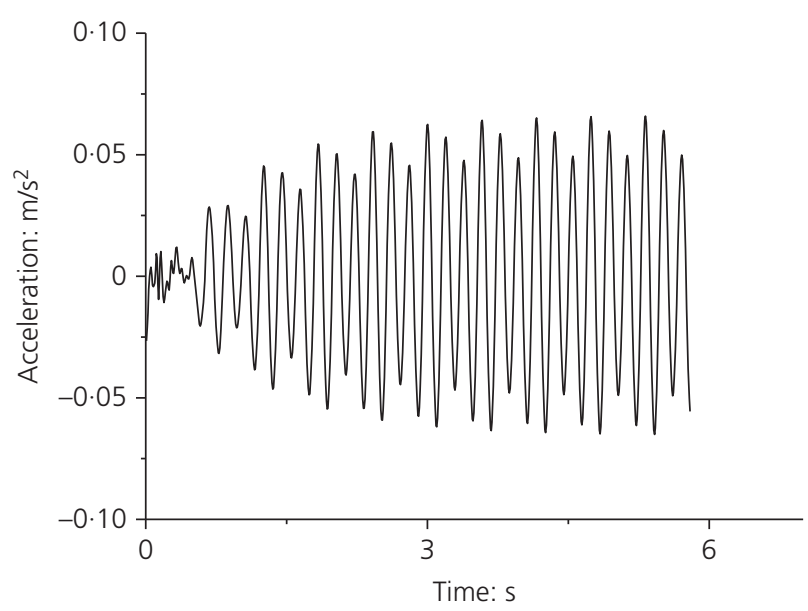

(a)

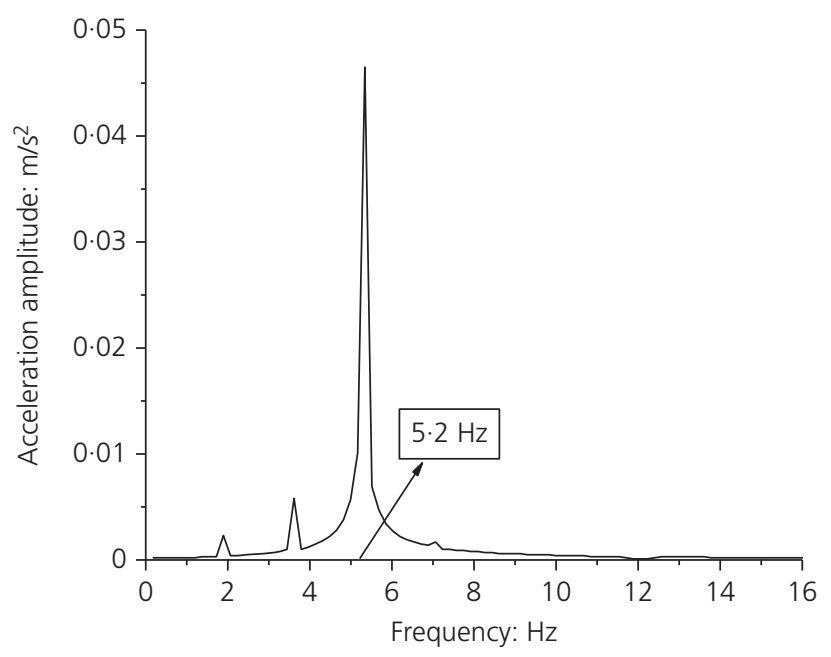

(b)

Figure 6. Response of one-unit floor system under human walking load: (a) time history-acceleration amplitude of point 1; (b) acceleration amplitude spectrum of point 1

vibration was almost as large as that of the first mode while, for points 3 and 4, the component of the third mode was smaller but cannot be ignored. The acceleration spectrum of point 1 shows two additional peaks at $1.6 \mathrm{~Hz}$ and $3.3 \mathrm{~Hz}$, which were caused by the first and second harmonics of the load. Similarly, this part of the vibration should also not be ignored. However, the vibration excited by the first and second harmonics of the load was negligible for the passive units.

\subsection{Parametric study and discussion}

\subsubsection{First natural frequency of the floor}

Among the factors that affect floor frequency, the floor span and the beam stiffness are the most significant. The influences of floor span and beam rigidity were studied considering an unfavourable load, meaning that the frequency of one of the load harmonics was the same as the first natural frequency of the floor. Dynamic response analyses were carried out on the one-unit floor system, in which the loading point and the damping ratio were consistent with those given in Section 3.1. Table 3 lists the fundamental frequencies and the peak accelerations of the one-unit floor system with different spans and beam stiffness under human walking load. It can be seen that the peak acceleration response decreased with an increase in the floor fundamental frequency. In addition, under the same excitation, the vibration response of the floor was approximately inversely proportional to the natural frequency.

\subsubsection{Load frequency}

As described in Section 3.1, the frequency of human walking has been found to vary in the range $1 \cdot 6-2 \cdot 4 \mathrm{~Hz}$. Loads with different frequencies may excite different floor modes. To investigate the effect of load frequency, the acceleration responses of the four-unit floor under human walking loads with various frequencies $(1 \cdot 63,1 \cdot 8,2 \cdot 0,2 \cdot 2$ and $2 \cdot 4 \mathrm{~Hz})$ applied at point 1 were considered. Figure 9 shows the acceleration responses of points $1-4$ of the four-unit floor system under these different loading frequencies.

In some cases, the peak acceleration response appeared before the steady stage (i.e. the transient stage). Taking the loading frequency of $1.8 \mathrm{~Hz}$ as an example, the time historyacceleration response at point 1 is shown in Figure 10. In the transient stage, the peak acceleration was $0.025 \mathrm{~m} / \mathrm{s}^{2}$, which is much larger than the steady response acceleration of $0.014 \mathrm{~m} / \mathrm{s}^{2}$. Although the transient response decayed rapidly, the peak acceleration at this stage will have an adverse effect on floors with a high degree of comfort requirements, such as operating rooms and precision instrument rooms. Therefore, the peak acceleration of the transient response stage should be considered for special-use buildings.

\subsubsection{Damping ratio}

Damping is a very important parameter in reducing excessive vibration responses in floor structures. However, precise values of the damping of concrete-steel-deck composite floor systems are mostly unknown as the value varies with the means of damping. A damping of $1.5 \%$ has been used for a composite steel-deck floor (SCI, 2009). However, it should be noted that this damping value could be smaller as external force-causing objects and other stationary objects will provide additional damping not included in this value. Higher damping can arise in a floor with permanent partitions, where it could be as much as 5-6\% (AISC, 1997). Elnimeiri and Iyengar (1989) recommended a damping coefficient of $4 \cdot 5-6 \%$ for finished floors with partitions while Brownjohn (2001) showed that the damping could increase to $10 \%$ depending on occupant position. On the other hand, previous studies carried out by Sachse (2002) and Ji (2003) proved that the presence of stationary humans will increase the damping of the structure by up to $12 \%$.

Therefore, in order to study the response of the floor system under different values of structural damping, five damping 


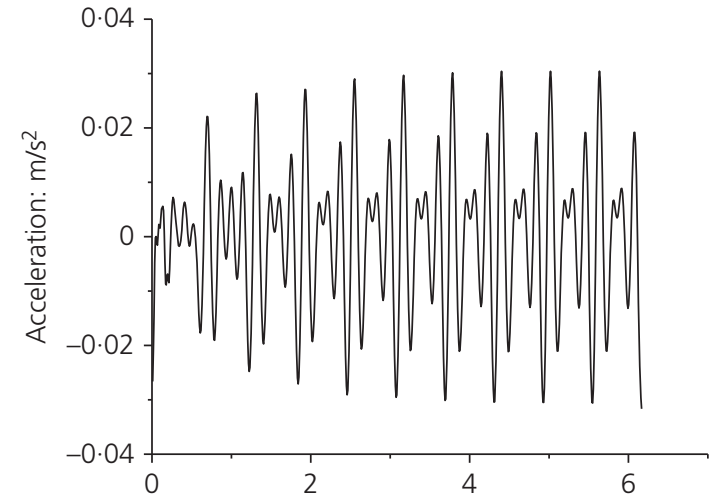

(a)

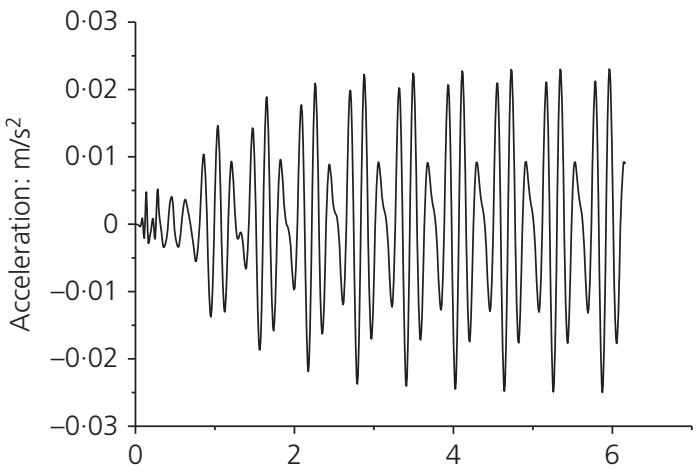

(c)

Time: $s$

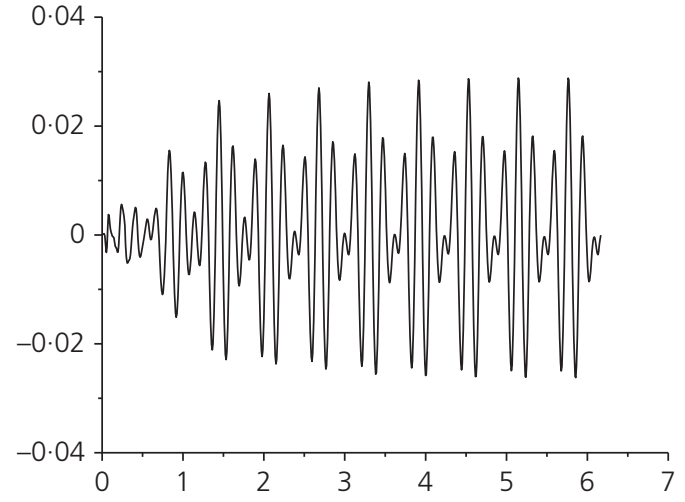

(b)

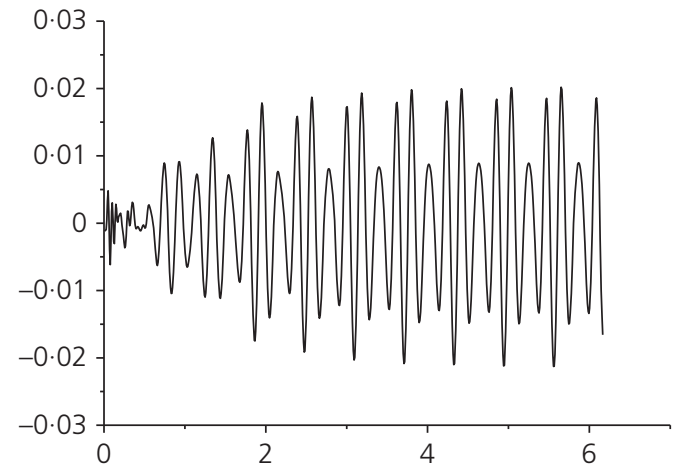

(d)

Time: $s$

Figure 7. Time history-acceleration response of four-unit floor system under human walking load: (a) point 1; (b) point 2; (c) point 3; (d) point 4

levels (3, 5, 8, 10 and 12\%) were considered in this study. Loads were applied at point 1 and the peak accelerations of points $1-4$ are shown in Figure 11. The figure shows that the peak acceleration decreased with an increase in damping ratio. However, the magnitude of the decrease reduced gradually and the amplitude of decrease of the active unit was smaller than that of the passive units. The results thus show that the effect of damping on the acceleration response of passive units is significant.

\subsubsection{Multi-person-induced vibrations}

In the analysis described thus far, a deterministic time domain load was used and loading was at a fixed point; this is equivalent to a single person's marking time (a military step in which soldiers march in place, moving their legs as in marching, but without stepping forward). However, in an actual situation, several people may walk on the floor simultaneously. The vibration response characteristics of the four-unit floor under a two-person walking load were thus studied considering the following two scenarios.

- Scenario 1: person A and person B walk at the same frequency and velocity, but $\mathrm{A}$ is in front of $\mathrm{B}$ and the time difference is $t$.
- Scenario 2: A and B walk side by side at the same speed but at different frequencies.

Tables 4 and 5 show the vibration responses of the floors under these two scenarios. The results indicate that, even if there is difference in time or frequency, the peak acceleration of the floor system in both cases is generally larger than that when only one person is walking. Current design standards only consider the walking vibration response induced by one person and do not consider the response of several people walking simultaneously. However, the analysis presented here indicates that multi-person walking excitation should be considered in the assessment of floor vibrations.

\subsubsection{Vibration of multi-floor buildings}

In a multi-floor building, the activities of humans on a floor will not only cause the vertical vibration of that floor but will also affect adjacent floors. In order to investigate the influence of load on an adjacent floor, a two-storey floor model was established (Figure 12). The parameters of each floor were identical to those given in Section 3.1. A walking load with a frequency of $1.72 \mathrm{~Hz}$ was applied at the mid-span of the second floor. The peak accelerations of the active floor and the 


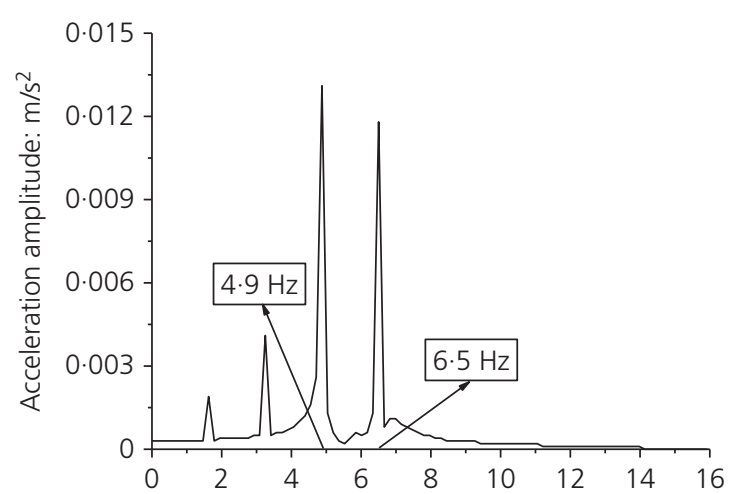

(a)

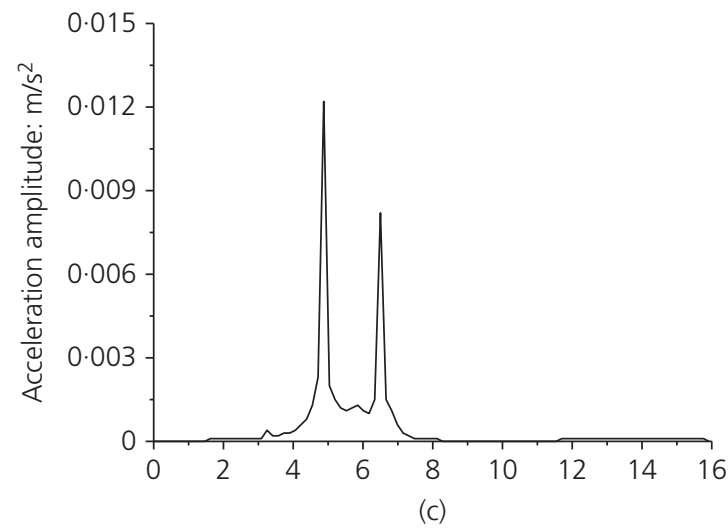

Frequency: $\mathrm{Hz}$

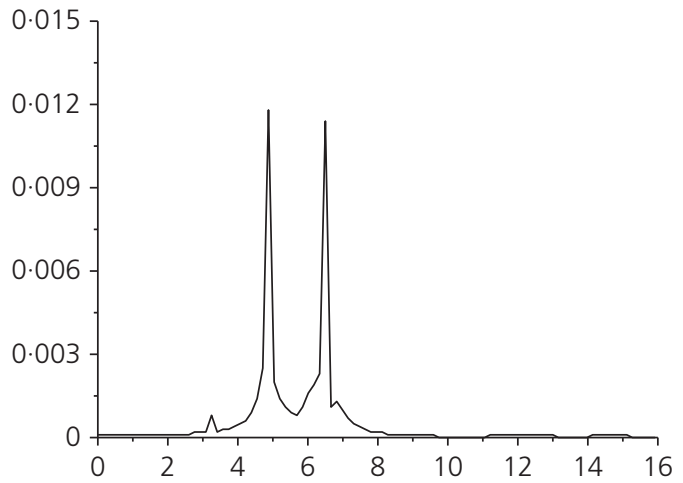

(b)

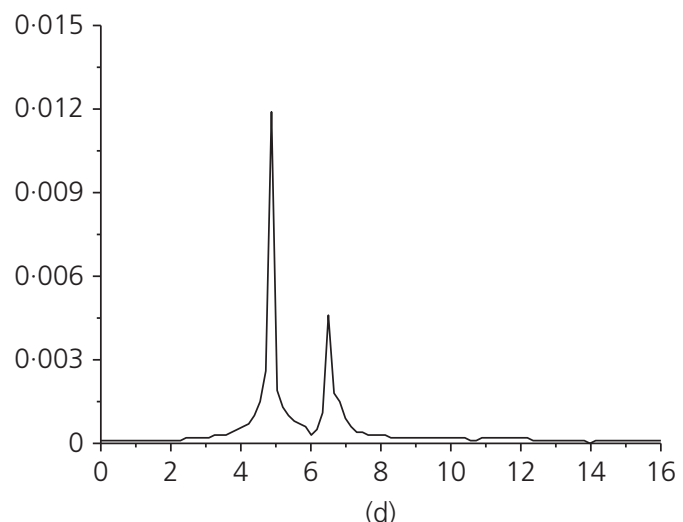

Frequency: $\mathrm{Hz}$

Figure 8. Acceleration spectrum of four-unit floor system under human walking load: (a) point 1; (b) point 2; (c) point 3; (d) point 4

Table 3. Effects of floor span and beam stiffness on the one-unit floor system under walking load

\begin{tabular}{|c|c|c|c|c|c|}
\hline \multicolumn{2}{|c|}{ Primary beam } & \multicolumn{2}{|c|}{ Secondary beam } & \multirow[b]{2}{*}{ Fundamental frequency: $\mathrm{Hz}$} & \multirow[b]{2}{*}{ Peak acceleration: $\times 10^{-2} \mathrm{~m} / \mathrm{s}^{2}$} \\
\hline Span: $m$ & Type & Span: $m$ & Type & & \\
\hline $6 \cdot 0$ & $\mid-45$ & $8 \cdot 2$ & $\mid-40$ & $8 \cdot 48$ & 3.04 \\
\hline $7 \cdot 0$ & |-45 & $8 \cdot 2$ & $\mid-40$ & 7.90 & $3 \cdot 20$ \\
\hline $8 \cdot 0$ & $\mathrm{l}-45$ & $8 \cdot 2$ & $\mathrm{I}-40$ & $7 \cdot 02$ & $4 \cdot 01$ \\
\hline $9 \cdot 0$ & $\mathrm{l}-45$ & $8 \cdot 2$ & $\mathrm{I}-40$ & $6 \cdot 25$ & $4 \cdot 80$ \\
\hline $10 \cdot 0$ & $\mathrm{l}-45$ & $8 \cdot 2$ & $\mathrm{I}-40$ & $5 \cdot 56$ & $5 \cdot 56$ \\
\hline $9 \cdot 0$ & $\mathrm{l}-45$ & $5 \cdot 6$ & $\mathrm{I}-40$ & $9 \cdot 62$ & $2 \cdot 45$ \\
\hline $9 \cdot 0$ & $\mathrm{l}-45$ & $6 \cdot 2$ & $\mathrm{I}-40$ & $8 \cdot 35$ & 3.05 \\
\hline $9 \cdot 0$ & $1-45$ & $7 \cdot 2$ & $\mathrm{I}-40$ & $7 \cdot 22$ & 3.98 \\
\hline 9.0 & $\mid-45$ & $8 \cdot 2$ & $\mid-40$ & $6 \cdot 25$ & 4.87 \\
\hline 9.0 & |-45 & $9 \cdot 2$ & $\mid-40$ & $5 \cdot 44$ & $5 \cdot 64$ \\
\hline $9 \cdot 0$ & $\mathrm{I}-40$ & $8 \cdot 2$ & $1-36$ & 4.63 & $7 \cdot 60$ \\
\hline $9 \cdot 0$ & $\mathrm{l}-45$ & $8 \cdot 2$ & $\mathrm{I}-40$ & $5 \cdot 16$ & $6 \cdot 40$ \\
\hline $9 \cdot 0$ & $1-50$ & $8 \cdot 2$ & $1-45$ & $5 \cdot 82$ & $5 \cdot 19$ \\
\hline $9 \cdot 0$ & $1-55$ & $8 \cdot 2$ & $1-50$ & $6 \cdot 51$ & $4 \cdot 08$ \\
\hline $9 \cdot 0$ & $1-60$ & $8 \cdot 2$ & I-55 & $7 \cdot 23$ & 3.29 \\
\hline 9.0 & I-65 & $8 \cdot 2$ & $\mathrm{I}-60$ & $7 \cdot 89$ & $2 \cdot 72$ \\
\hline
\end{tabular}

passive floor were found to be $6.45 \times 10^{-2} \mathrm{~m} / \mathrm{s}^{2}$ and $0 \cdot 16 \times 10^{-2} \mathrm{~m} / \mathrm{s}^{2}$, respectively, and it can thus be concluded that the response of the adjacent floor induced by vibration of the active floor is negligible.

\section{Floor vibrations under rhythmic activity}

Floor vibration induced by rhythmic activities such as dancing, running, jumping and aerobics is a very complex problem. The current investigation considered human actions 


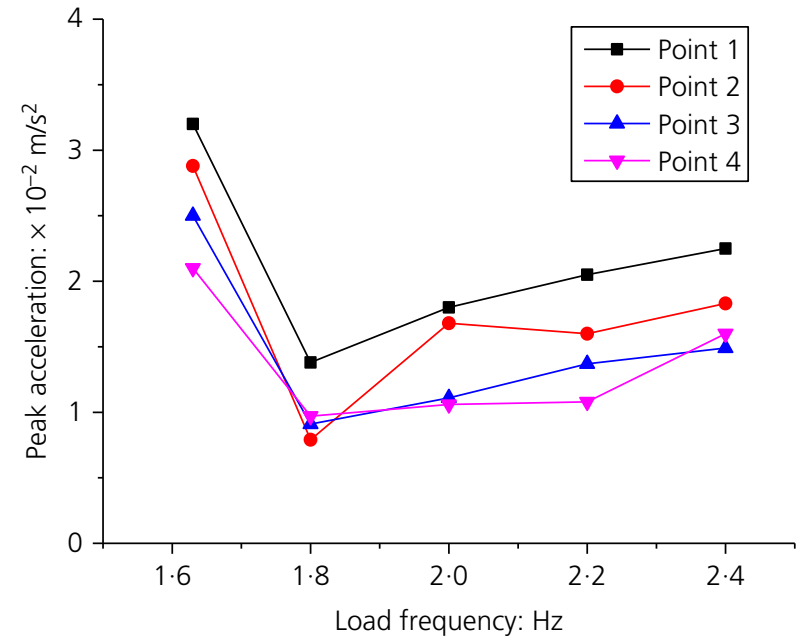

Figure 9. Peak acceleration of four-unit floor system under different load frequencies

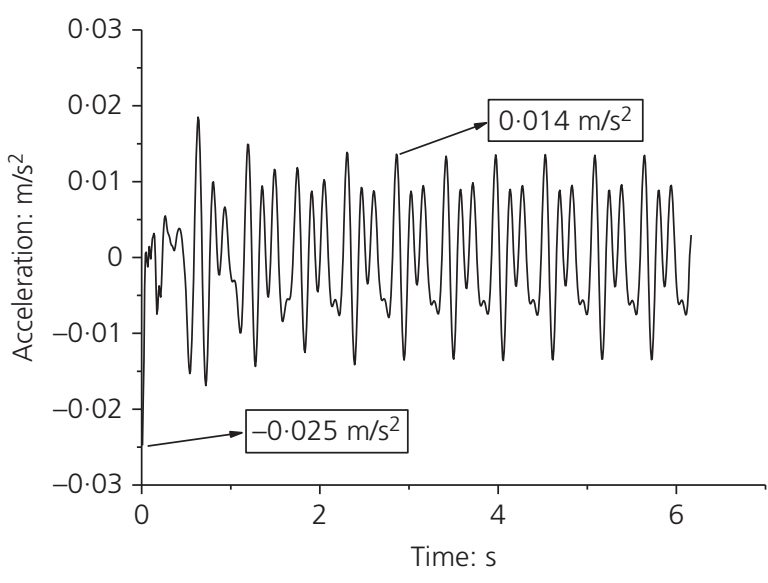

Figure 10. Time history-acceleration response of point 1 under walking load with frequency of $1.8 \mathrm{~Hz}$

of jumping or aerobics as this type of activity produces higher loads than people walking. Two representations of rhythmic load were considered in this study.

The first representation of rhythmic load considered was the half-sine wave form, suggested by Ji and Ellis (1994), and described by

2. $F(t)= \begin{cases}\frac{\pi G}{2 \alpha} \sin \left(\pi t / t_{\mathrm{p}}\right) & 0 \leq t \leq t_{\mathrm{p}} \\ 0 & t_{\mathrm{p}} \leq t \leq T_{\mathrm{p}}\end{cases}$

In this load model, the load-time history was modelled as a function with two parts: (a) a force function to simulate the

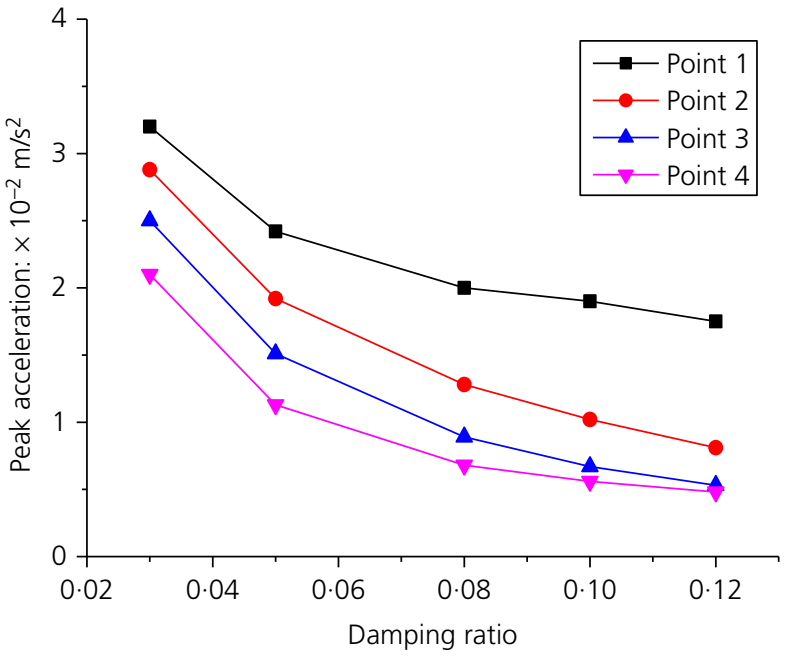

Figure 11. Peak acceleration of four-unit floor system with different damping ratios

Table 4. Comparison of one person and multi-person walking in scenario 1

\begin{tabular}{lcccc} 
& \multicolumn{4}{c}{ Peak acceleration: $\times \mathbf{1 0}^{-\mathbf{2}} \mathbf{~} \mathbf{~} / \mathbf{s}^{\mathbf{2}}$} \\
\cline { 2 - 5 } & Point 1 & Point 2 & Point 3 & Point 4 \\
\hline One person & 3.20 & 2.88 & 2.50 & 2.10 \\
Time difference $=0$ & 6.25 & 5.75 & 5.00 & 4.30 \\
Time difference $=0.25 t$ & 4.57 & 4.76 & 4.00 & 3.46 \\
Time difference $=0.50 t$ & 3.39 & 2.88 & 2.05 & 1.51
\end{tabular}

Table 5. Comparison of one person and multi-person walking in scenario 2

\begin{tabular}{|c|c|c|c|c|}
\hline & \multicolumn{4}{|c|}{ Peak acceleration: $\times 10^{-2} \mathrm{~m} / \mathrm{s}^{2}$} \\
\hline & Point 1 & Point 2 & Point 3 & Point 4 \\
\hline One person & $3 \cdot 20$ & $2 \cdot 88$ & $2 \cdot 50$ & $2 \cdot 10$ \\
\hline $\begin{array}{l}\text { Walking frequencies = } \\
1.63 \mathrm{~Hz} \text { and } 1.63 \mathrm{~Hz}\end{array}$ & $6 \cdot 25$ & $5 \cdot 75$ & $5 \cdot 00$ & $4 \cdot 30$ \\
\hline $\begin{array}{l}\text { Walking frequencies }= \\
2.40 \mathrm{~Hz} \text { and } 1.63 \mathrm{~Hz}\end{array}$ & $4 \cdot 00$ & 4.06 & $3 \cdot 52$ & $3 \cdot 12$ \\
\hline $\begin{array}{l}\text { Walking frequencies = } \\
2.00 \mathrm{~Hz} \text { and } 1.63 \mathrm{~Hz}\end{array}$ & $4 \cdot 15$ & 4.00 & $3 \cdot 20$ & $3 \cdot 04$ \\
\hline $\begin{array}{l}\text { Walking frequencies = } \\
1.80 \mathrm{~Hz} \text { and } 1.63 \mathrm{~Hz}\end{array}$ & $4 \cdot 20$ & $3 \cdot 50$ & $3 \cdot 26$ & $2 \cdot 50$ \\
\hline
\end{tabular}

load applied when the feet are in contact with the floor for a time phase, which is called the contact duration, followed by $(b)$ zero force when the feet are off the floor. In this analysis, the foot contact ratio $\alpha=0.5$, describing the rhythmic activity of normal jumping or high-impact aerobics, and $G=0.2 \mathrm{kPa}$, corresponding to one person per $3.5 \mathrm{~m}^{2}$ of floor space, assuming the average weight of the person to be $70 \mathrm{~kg}$. 


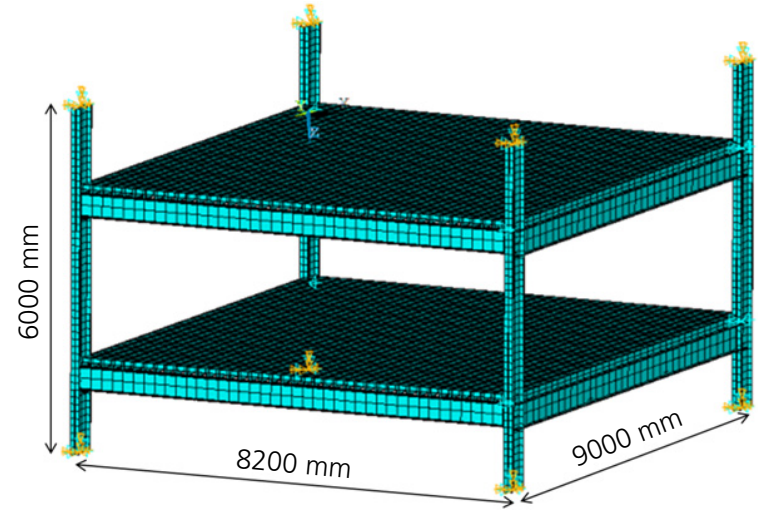

Figure 12. Two-storey model

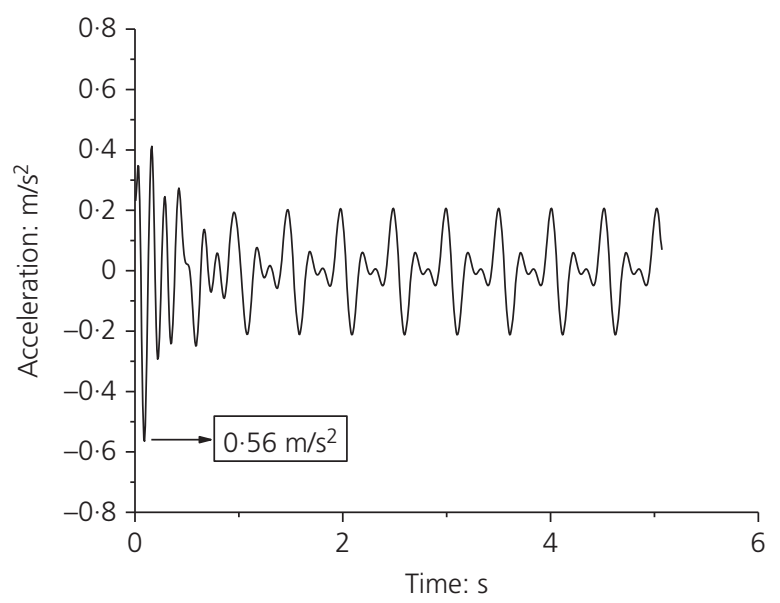

(a)

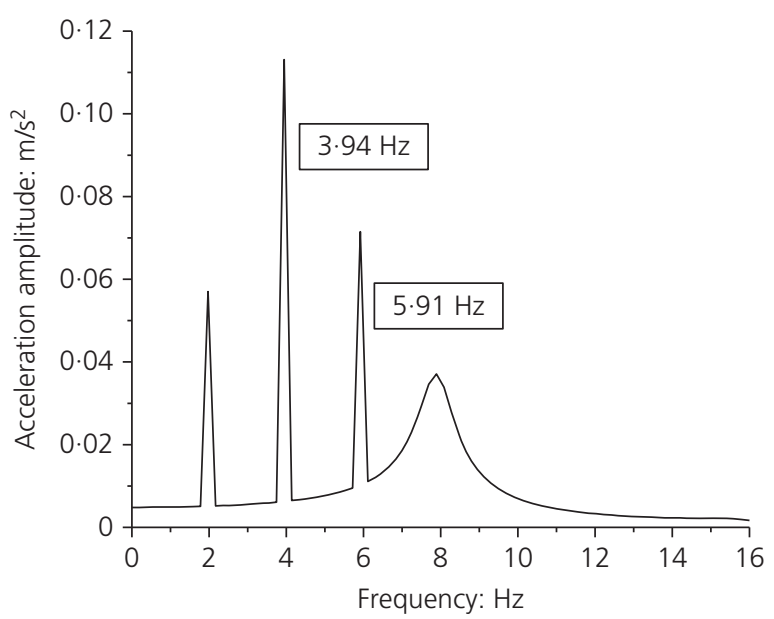

(b)

Figure 13. Response of point 1 of the one-unit floor under Fourier amplitude wave load: (a) time history-acceleration response; (b) acceleration spectrum

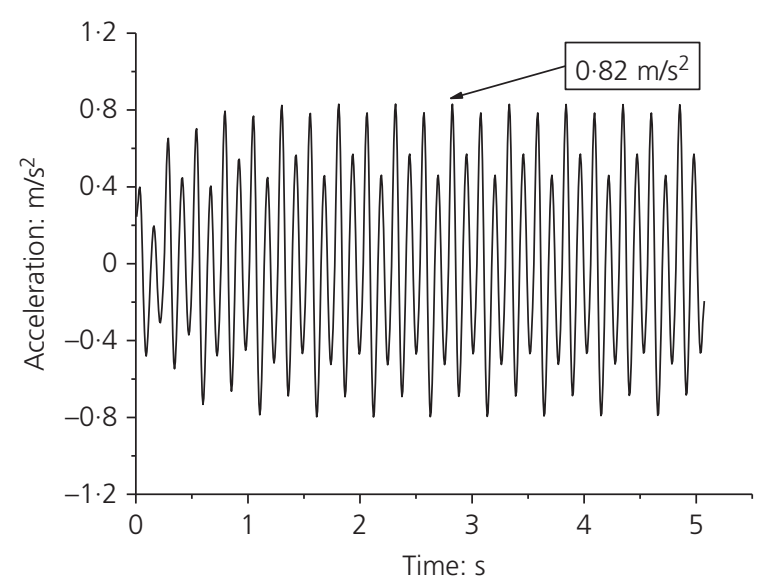

(a)

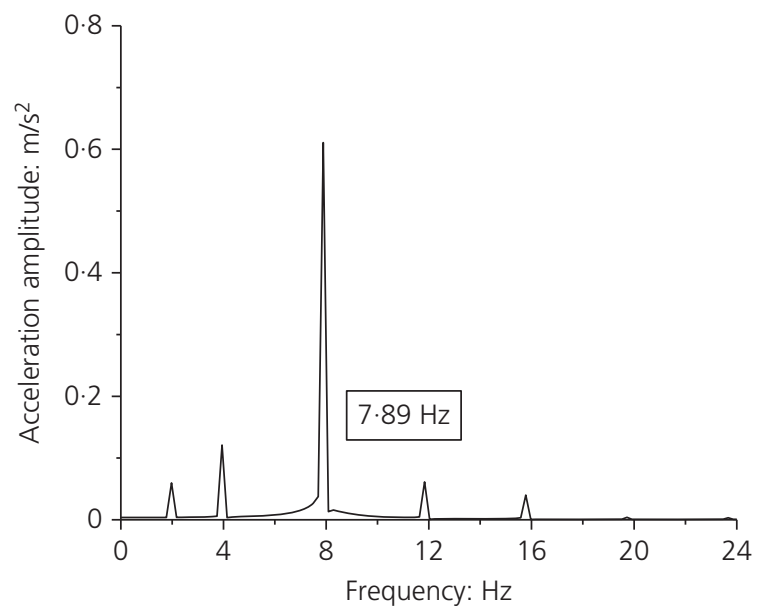

(b)

Figure 14. Response of point 1 of the one-unit floor under half-sine wave load: (a) time history-acceleration response; (b) acceleration spectrum

The second representation of rhythmic load considered was the form of a series of harmonic waves, as adopted by AISC (1997) and expressed as

3. $P(t)=w_{\mathrm{p}}\left[1+\sum \alpha_{i} \cos \left(2 \pi f_{i} t+\phi_{i}\right)\right]$

The current investigation used human actions of jumping or aerobics and thus the corresponding Fourier coefficients $\left(\alpha_{i}\right)$ were $1 \cdot 5,0 \cdot 6$ and $0 \cdot 1$ for $\alpha_{1}, \alpha_{2}$ and $\alpha_{3}$, respectively (Ginty et al., 2001). It was assumed that all the Fourier components of the load-time history were in phase during the activity and thus the phase lag was zero. Therefore, perfect coordination between the occupants carrying out the activity was considered.

\subsection{One-unit floor}

Since rhythmic activities usually generate higher dynamic loads, the primary and secondary beams were changed to I-65 


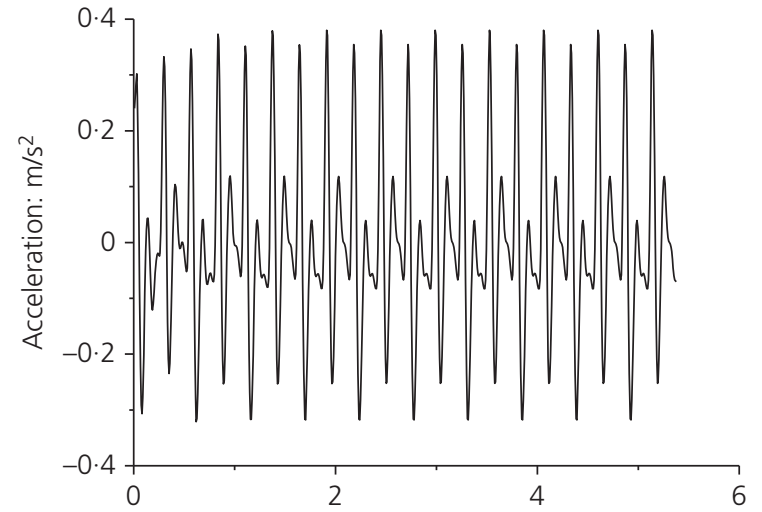

(a)

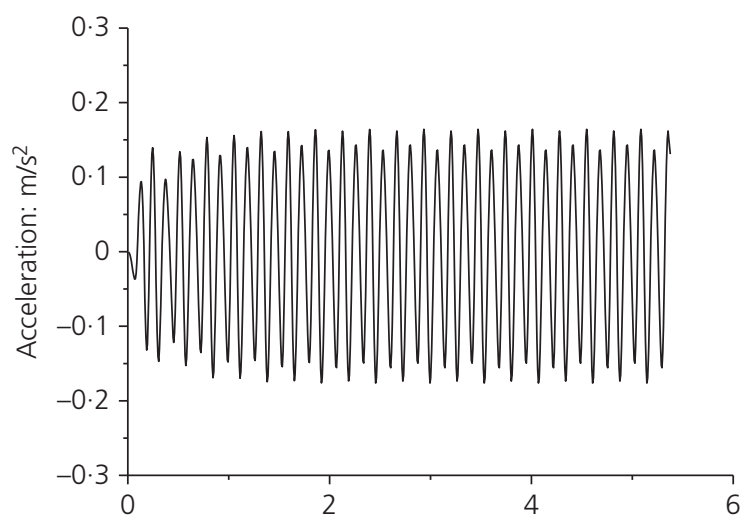

(c)

Time: $s$

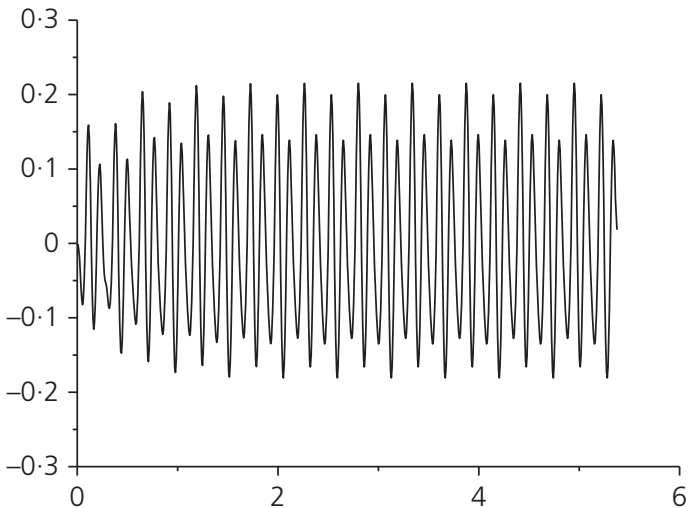

(b)

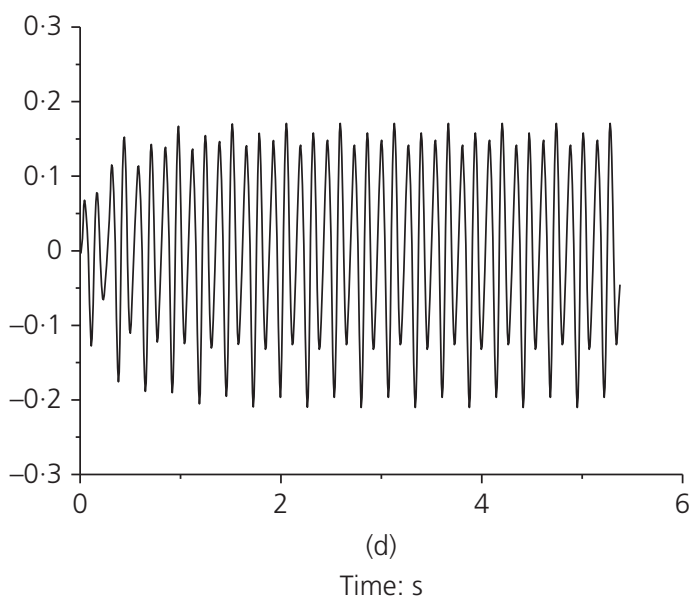

Figure 15. Time history-acceleration response of four-unit floor system under half-sine wave load: (a) point 1; (b) point 2; (c) point 3; (d) point 4

and I-60 beams. The structural arrangement of the floor, the size of the steel sheet and the columns were the same as those given in Section 3.1. The first four natural frequencies of the enhanced one-unit floor were determined to be $7 \cdot 89,13 \cdot 17$, 14.45 and $16.64 \mathrm{~Hz}$, respectively. In the dynamic analysis of the one-unit floor, the load frequency was taken as $7 \cdot 89 / 4=1.97 \mathrm{~Hz}$ and the damping ratio was 0.06 .

\subsubsection{Fourier wave load}

The first three harmonics of the Fourier amplitude wave load were applied to the whole floor. Figure 13 shows the time history-acceleration response and the acceleration spectrum of point 1 . The peak acceleration of the transient response stage was $0.56 \mathrm{~m} / \mathrm{s}^{2}$ and the steady-state response acceleration peak was $0.22 \mathrm{~m} / \mathrm{s}^{2}$. According to the acceleration spectrum, the second-order harmonic wave caused the maximum acceleration response.

\subsubsection{Half-sine wave load}

The half-sine wave load with a contact ratio $(\alpha)$ of 0.5 was applied to the whole floor and the acceleration responses are shown in Figure 14. A comparison of Figures 13 and 14 shows that the vibration response was quite different with the application of different loads. The peak acceleration of the floor under the half-sine wave load was $0.82 \mathrm{~m} / \mathrm{s}^{2}$, which is much larger than that under the Fourier amplitude wave load $\left(0.22 \mathrm{~m} / \mathrm{s}^{2}\right)$. This is because the first mode is excited under the half-sine load, which is the main component of vibration, while the Fourier wave load does not contain the component that could excite the resonance reaction. According to AISC (1997), the limit value for acceleration is $0 \cdot 4-0.7 \mathrm{~m} / \mathrm{s}^{2}$ under rhythmic activities, and obviously the considered floor does not meet the standard of comfort. It is thus very important to choose an appropriate load model in calculating and controlling floor vibration responses.

\subsection{Four-unit floor}

The first natural frequency of the enhanced four-unit floor was $7.44 \mathrm{~Hz}$. The analysis of the one-unit floor revealed that the vibration response of the floor under the half-sine wave load was unfavourable and therefore only the half-sine wave load was considered in the analysis of the four-unit floor. 


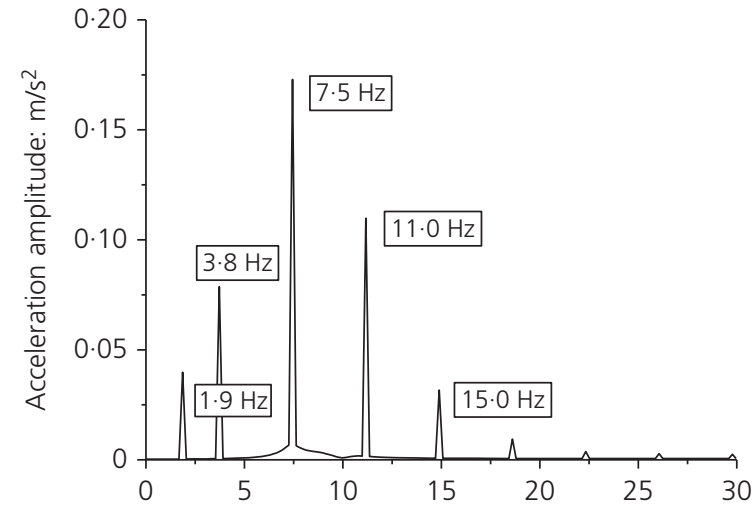

(a)

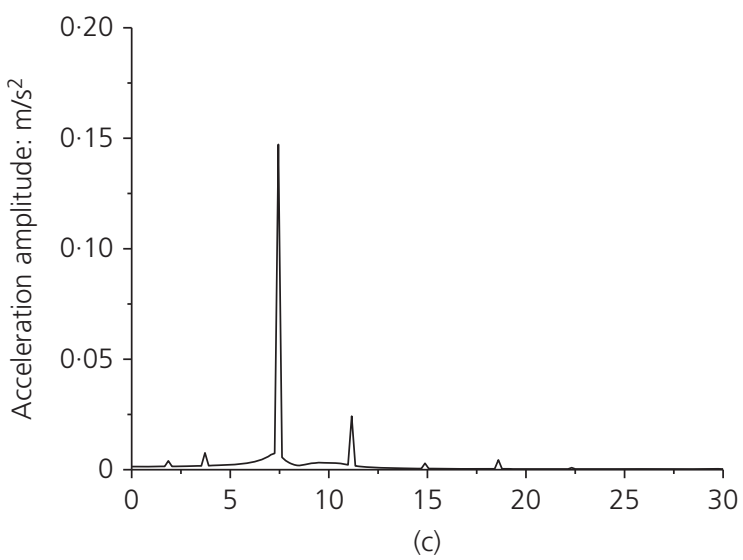

Frequency: $\mathrm{Hz}$

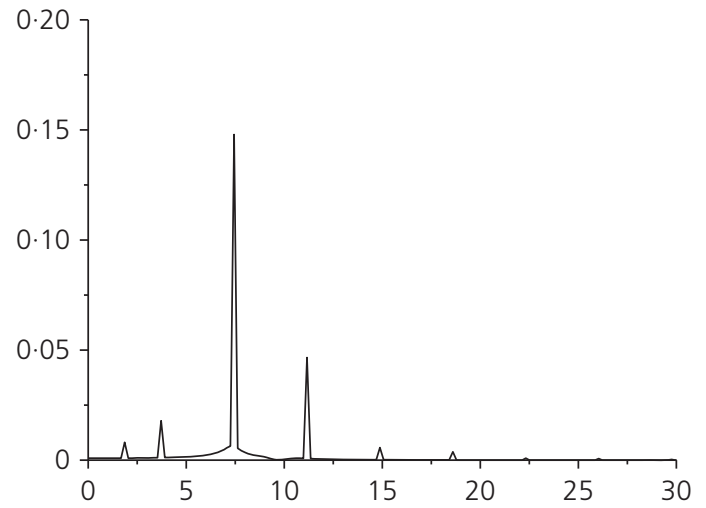

(b)

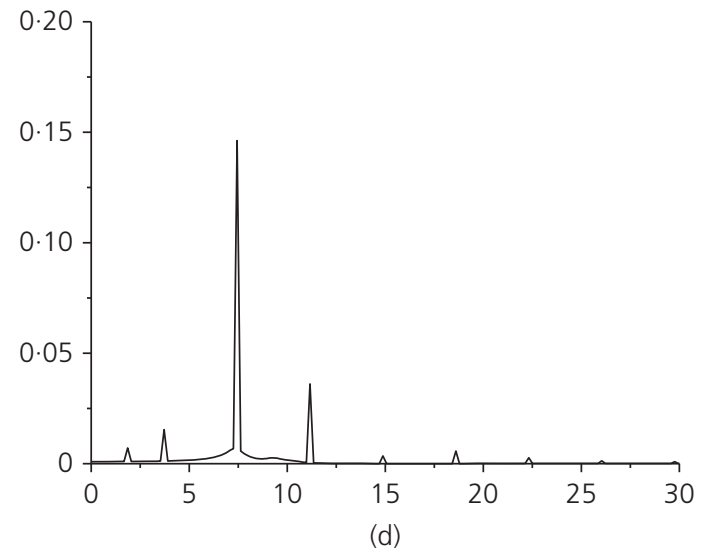

Frequency: $\mathrm{Hz}$

Figure 16. Acceleration amplitude of four-unit floor system under half-sine wave load: (a) point 1; (b) point 2; (c) point 3; (d) point 4

The load was applied at point 1 , with a frequency of $1.86 \mathrm{~Hz}$ $(7 \cdot 44 / 4)$ and a contact ratio of 0.5 . The peak accelerations of points 1-4 were determined to be $0 \cdot 38,0 \cdot 22,0 \cdot 17$ and $0.21 \mathrm{~m} / \mathrm{s}^{2}$, respectively. Similar to the vibration response of the floor under walking load, the vibration of the active unit (point 1) was slightly greater than that of the passive units (points 2-4). The acceleration responses and acceleration amplitudes are shown in Figures 15 and 16.

As shown in Figure 16, loading frequencies of $7 \cdot 5$, 11.0 and $15.0 \mathrm{~Hz}$ produced peak amplitudes in the acceleration, meaning that the first mode and higher modes of the floor are excited. There were also peaks in the spectrum of point 1 at frequencies of 1.9 and $3.8 \mathrm{~Hz}$, which are caused by the lower harmonics of the load (i.e. first and second). For the passive units (points 2-4), the vibration of the first-order mode was the main vibration, but the highorder harmonic component of the load also caused a large acceleration response. However, the vibration response caused by the low-order harmonic component of the load was negligible.

\subsection{Parametric study and discussion}

\subsubsection{Load area}

In the analysis described in Section 4.1, the load was applied to the entire floor. In practice, however, the load area changes with the number of people participating in the activity. The vibration response of the one-unit floor system under different load areas was therefore studied. The load area is shown in Figure 17. Four different areas were considered: $a=L_{1} / 4$, $b=L_{2} / 4 ; a=L_{1} / 2, b=L_{2} / 2 ; a=3 L_{1} / 4, b=3 L_{2} / 4 ; a=L_{1}, b=L_{2}$. The load was in the form of half-sine wave, in which the contact rate was 0.5 and the uniform load was $0.2 \mathrm{kPa}$.

Table 6 lists the peak accelerations at mid-span for the different load areas, and shows that the peak acceleration response increased with an increase in load area. The damping ratio was taken as a constant factor 0.06 in the analysis. However, in an actual situation, an increase in load area means an increased number of people involved in the activity, which would lead to an increase in the damping ratio and thus a positive effect on reducing the vibration response of the floor. 


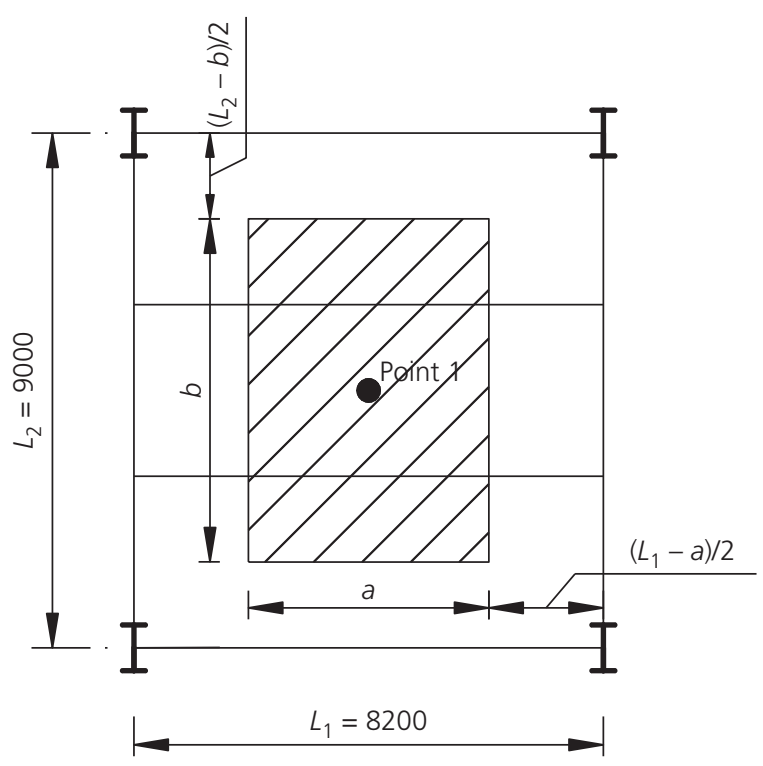

Figure 17. Schematic illustration of load area

\subsubsection{Load frequency and contact ratio}

Taking into account the fact that load frequency and contact ratio will vary with the type of activity, six different contact ratios and three kinds of load frequency were analysed. The peak acceleration responses of the one-unit floor system under different load frequencies and contact ratios are shown in Figure 18. On the whole, the vibration response shows a decreasing trend with increasing contact ratio, except for a contact ratio of $0 \cdot 5$. Since the third-order harmonic component of the half-sine load is zero at a foot contact ratio of $0.5(\mathrm{Ji}$ and Ellis, 1994), the absence of the third-order harmonic component will lead to a smaller floor acceleration response.

\subsubsection{Floor span}

The vibration responses of the enhanced one-unit floors with different floor spans were also assessed. The fourth harmonic of the load was the same as the natural frequency of the floor and the values of uniform load and damping ratio were consistent with those given in Section 4. The fundamental frequencies and peak accelerations of the one-unit floor system with different beam spans under rhythmic load are shown in Table 7. As shown in the table, there was no significant difference in the acceleration response of the floors with different spans, with peak accelerations of about $0.8 \mathrm{~m} / \mathrm{s}^{2}$. In this case, the floor's first natural mode was excited by the fourth harmonic of the load and the first mode of vibration was the main component of the whole vibration. Although the load frequency was different, the amplitude of the fourth load harmonic was constant. Therefore, the peak accelerations of the floors with different spans under different loads were nearly the same. However, in a multi-unit floor system where higher modes may be excited, the effect of the floor span on the acceleration response needs to be analysed further.
Table 6. Peak accelerations at mid-span under different load areas

$\begin{array}{lc}\text { Load area } & \text { Peak acceleration: } \mathbf{m} / \mathbf{s}^{\mathbf{2}} \\ a=L_{1} / 4, b=L_{2} / 4 & 0.16 \\ a=L_{1} / 2, b=L_{2} / 2 & 0.32 \\ a=3 L_{1} / 4, b=3 L_{2} / 4 & 0.60 \\ a=L_{1}, b=L_{2} & 0.82\end{array}$

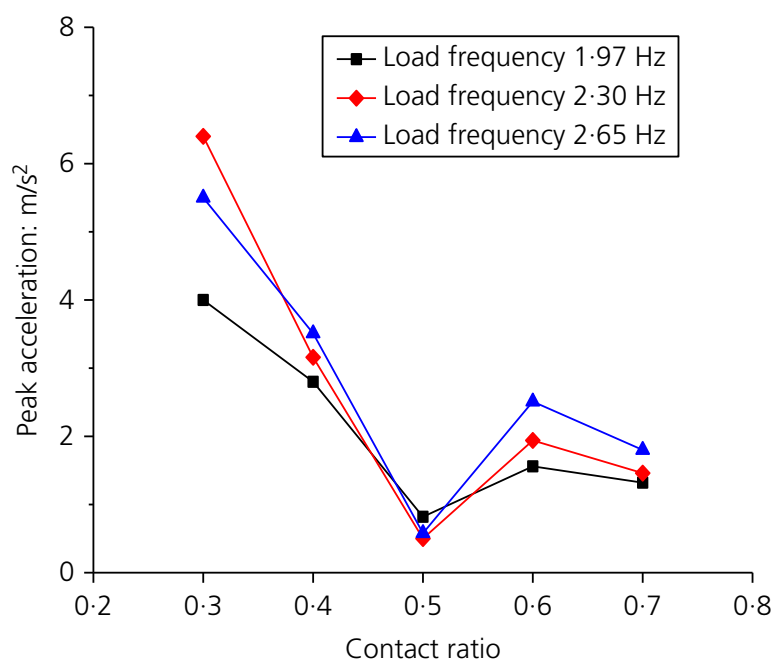

Figure 18. Peak acceleration of one-unit floor system under different load frequencies and contact ratios

\subsubsection{Damping ratio}

Figure 19 shows the peak acceleration responses of the fourunit floor system with different damping ratios. The effect of damping ratio on the vibration of the floor under rhythmic activity was similar to that under walking load, which was discussed in Section 3.3.

\subsubsection{Multi-floor system}

A two-floor system model was analysed and each floor had the same parameters as given in Section 4.1. The half-sine wave load was applied to the second floor. The peak acceleration responses of the active and passive floors were $0.88 \mathrm{~m} / \mathrm{s}^{2}$ and $0.04 \mathrm{~m} / \mathrm{s}^{2}$, respectively. Similar to the situation under walking load, the vibration responses differed by an order of magnitude in terms of the peak acceleration. However, since the vibration response induced by rhythmic activity is significant, the vibration of the adjacent passive floor should not be ignored in the floor vibration assessment. For instance, the peak acceleration of the passive floor in this analysis $\left(0.04 \mathrm{~m} / \mathrm{s}^{2}\right)$ was very close to the allowable acceleration for an office floor (AISC, 1997). Therefore, in an assessment of the vibration response of a multi-floor building, different acceleration criteria should be used for evaluation according to the floor's function and the vibration of adjacent passive floors needs to be considered. 
Table 7. Effect of floor span on one-unit floor system under rhythmic load

\begin{tabular}{|c|c|c|c|c|c|}
\hline \multicolumn{2}{|c|}{ Primary beam } & \multicolumn{2}{|c|}{ Secondary beam } & \multirow[b]{2}{*}{ Fundamental frequency: $\mathrm{Hz}$} & \multirow[b]{2}{*}{ Peak acceleration: $\mathrm{m} / \mathrm{s}^{2}$} \\
\hline Span: $m$ & Type & Span: $m$ & Type & & \\
\hline $6 \cdot 0$ & $1-65$ & $8 \cdot 2$ & $1-60$ & $12 \cdot 79$ & 0.83 \\
\hline $7 \cdot 0$ & $1-65$ & $8 \cdot 2$ & $1-60$ & $10 \cdot 93$ & 0.82 \\
\hline $8 \cdot 0$ & $1-65$ & $8 \cdot 2$ & $1-60$ & $9 \cdot 35$ & 0.83 \\
\hline 9.0 & I-65 & 8.2 & I-60 & $7 \cdot 89$ & 0.82 \\
\hline $10 \cdot 0$ & $1-65$ & 8.2 & I-60 & 6.92 & 0.83 \\
\hline 9.0 & I-65 & $5 \cdot 2$ & I-60 & $10 \cdot 6$ & 0.77 \\
\hline $9 \cdot 0$ & I-65 & $6 \cdot 2$ & I-60 & 9.93 & 0.79 \\
\hline $9 \cdot 0$ & $1-65$ & $7 \cdot 2$ & $1-60$ & 8.92 & 0.80 \\
\hline $9 \cdot 0$ & I-65 & $8 \cdot 2$ & I-60 & $7 \cdot 89$ & 0.82 \\
\hline $9 \cdot 0$ & $1-65$ & $9 \cdot 2$ & $1-60$ & $7 \cdot 20$ & $0 \cdot 86$ \\
\hline
\end{tabular}

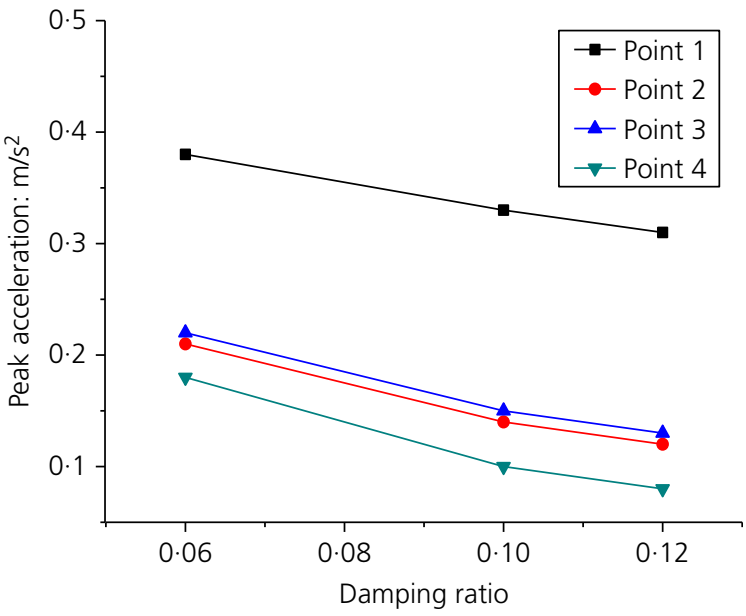

Figure 19. Peak acceleration of four-unit floor system with different damping ratios

\subsection{Criteria and human comfort evaluation}

Human perception to comfort in terms of acceleration response is the criterion used in design evaluations of composite floors. In terms of vibration serviceability due to human rhythmic activities, the comfort index can be used to evaluate human perception to the vibration of composite floors. One important step in this procedure is to determine the peak accelerations of composite floors, which can be achieved based on the developed FE models. The evaluation of the maximum peak unweighted acceleration may represent a very conservative analysis, whereas the dynamic response quickly enters the steady state. In this context, an evaluation in terms of amplitude in the steady state is more reasonable. Generally, the human comfort limit of $0.5 \mathrm{~m} / \mathrm{s}^{2}$ is recommended to prevent excessive vibrations on areas near where rhythmic activity is taking place (AISC, 1997).

\section{Conclusions}

A finite-element study was conducted to investigate the vibration behaviour of one-unit and four-unit steel-deck composite floors under human walking and rhythmic activities. The conclusions drawn from this study are as follows.

(a) For multi-unit composite floor systems with a relatively uniform stiffness distribution, the first few natural frequencies are very close, showing the phenomenon of mode concentration. Vibration of the high-order mode is easily excited under human walking or rhythmic activities. The vibration components of the higher modes are significant and should not be ignored in an assessment of floor vibration response.

(b) Loads, which are the source of excitation, play an important role in the dynamic behaviour of composite floors. It is very important to choose an appropriate load model to evaluate the vibration response of the floor. In this study, the human walking frequency was considered to be in the range $1 \cdot 6-2 \cdot 4 \mathrm{~Hz}$ and the rhythmic load was represented as a half-sine wave and a simple harmonic wave. The floor's natural frequency, effective weight and damping ratio are also influencing factors.

(c) In some cases, the peak acceleration in the transient response stage was found to be much greater than that in the steady stage. Although the transient response decays rapidly, the peak acceleration in this stage will have an adverse effect on floors that have a high degree of comfort requirements, such as operating rooms and precision instrument rooms. Therefore, for special-use buildings, the peak acceleration of the transient response stage should be considered.

(d) In a multi-unit composite floor system, the vibration of the passive units should not be ignored because the vibrations of the active unit and the adjacent passive units are of the same order of magnitude in terms of peak acceleration. The vibration response of each adjacent passive floor unit should be evaluated according to its function.

(e) In an assessment of the vibration response of a multi-floor building under rhythmic activities, different acceleration criteria should be used for evaluation according to the floor function and the vibration of adjacent passive floors should 
also be considered. However, under human walking load, this passive vibration can be neglected.

\section{Acknowledgement}

The authors greatly appreciate the support of the High Peak Discipline Research of the Science and Technology Commission of Shanghai Municipality. The funding, cooperation and assistance of many people from the organisation are gratefully acknowledged.

\section{REFERENCES}

AISC (American Institute of Steel Construction) (1997) AISC/CISC

Steel design guide series 11: Floor vibrations due to human activity. AISC, Chicago, IL, USA.

An Q, Chen Z, Ren Q, Liu H and Yan X (2015) Control of human-induced vibration of an innovative CSBS-CSCFS. Journal of Constructional Steel Research 115(12): 359-371.

An Q, Ren Q, Liu H, Yan X and Chen Z (2016) Dynamic performance characteristics of an innovative cable supported beam structureconcrete slab composite floor system under human-induced loads. Engineering Structures 117(6): 40-57.

Behnia A, Chai HK, Ranjbar N and Behnia N (2013) Finite element analysis of the dynamic response of composite floors subjected to walking induced vibrations. Advances in Structural Engineering 16(5): 959-974

Brownjohn JMW (2001) Energy dissipation from vibrating floor slabs due to human-structure interaction. Shock \& Vibration 8(6): 315-323.

BSI (2008) BS 6472-1:2008: Guide to evaluation of human exposure to vibration in buildings ( $1 \mathrm{~Hz}$ to $80 \mathrm{~Hz}$ ). BSI, London, UK.

Chen SM and Zhang J (2012) Vibration characteristics of concrete-steel composite floor structures. Discussion. ACI Structural Journal 109(5): 741-743.

Costa-Neves LF, Silva JGSD, Lima LROD and Jordão S (2014) Multi-storey, multi-bay buildings with composite steel-deck floors under human-induced loads: the human comfort issue. Computers \& Structures 136(3): $34-46$.

Ebrahimpour A and Sack RL (2003) A survey of vibration serviceability criteria for structures. In Proceedings of the Ninth International Conference on Civil and Structural Engineering Computing. Civil-Comp, Egmond-aan-Zee, Netherlands, pp. 177-179.

El-Dardiry E and Ji T (2006) Modelling of the dynamic behaviour of profiled composite floors. Engineering Structures 28(4): 567-579.

El-Dardiry E, Wahyuni E, Ji T and Ellis BR (2002) Improving FE models of a long-span flat concrete floor using natural frequency measurements. Computers \& Structures 80(27-30): 2145-2156.

Elnimeiri M and lyengar H (1989) Steel Structures. American Society of Civil Engineers, San Francisco, CA, USA.

Gaspar CMR, Silva JGSD and Costa-Neves LF (2016) Multimode vibration control of building steel-concrete composite floors submitted to human rhythmic activities. Computers \& Structures 165(3): $107-122$.

Ginty D, Derwent JM and Ji T (2001) The frequency ranges of dance-type loads. The Structural Engineer 79(6): 27-31.

Ji T (2003) Understanding the interactions between people and structures. The Structural Engineer 81(14): 12-13.

Ji T and Ellis BR (1994) Floor vibrations induced by dance type loads - verification. The Structural Engineer 72(3): 45-50.

Liu D and Davis B (2012) Investigation of the accuracy of vibration response prediction methods for high frequency floors. In Structures Congress 2012. ASCE, Chicago, USA, pp. 875-885.

Mello AVA, Silva JGSD, Vellasco PCGDS, Andrade SALD and Lima LROD (2008) Dynamic analysis of composite systems made of concrete slabs and steel beams. Journal of Constructional Steel Research 64(10): 1142-1151.

Pavic A, Miskovic Z and Reynolds P (2007) Modal testing and finite-element model updating of a lively open-plan composite building floor. Journal of Structural Engineering 133(4): $550-558$.

Racic V, Pavic A and Brownjohn JMW (2009) Experimental identification and analytical modelling of human walking forces: literature review. Journal of Sound and Vibration 16(326): 1-49.

Reynolds P, Díaz IM and Nyawako DS (2009) Vibration testing and active control of an office floor. In Proceedings of IMAC-XXVII: Conference \& Exposition on Structural Dynamics. Society for Experimental Mechanics, Orlando, FL, USA, pp. 586-595.

Sachse R (2002) Modelling effects of human occupants on modal properties of slender structures. The Structural Engineer 80(5): 2 .

Santos MDSD, Daniel VFL, Carmona JEC, Avila SM and Carvalho GNDD (2013) Vibration control of a gym floor using tuned mass dampers: a numerical analysis. Modern Mechanical Engineering 3(3): 9-16.

SCI (Steel Construction Institute) (2009) SCI P354: Design of floors for vibration: a new approach (revised edition). SCI, Ascot, UK.

Silva SSD (2006) Vibration Characteristics of Steel-deck Composite Floor Systems Under Human Excitation. PhD thesis, Queensland University of Technology, Brisbane, Australia.

Silva SSD and Thambiratnam DP (2009) Dynamic characteristics of steel-deck composite floors under human-induced loads. Computers \& Structures 87(17-18): 1067-1076.

Silva SSD and Thambiratnam DP (2011) Vibration characteristics of concrete-steel composite floor structures. ACI Structural Journal 108(6): 706-714.

Varela WD and Battista RC (2011) Control of vibrations induced by people walking on large span composite floor decks. Engineering Structures 33(9): 2485-2494. 